\title{
Development of enzyme-linked immunosorbent assays based on recombinant MSP1a and MSP2 of Anaplasma marginale
}

\author{
Flábio R Araújo/ ${ }^{+}$, Valeska SP Melo*, Carlos AN Ramos/ ${ }^{++}$, Claudio R Madruga, \\ Cleber 0 Soares, Raul H Kessler, Nalvo F Almeida**, Graziela S Araújo**, Leucio C Alves*, \\ Roberto AA Torres Júnior, Stênio P Fragoso***, Paulo RC Arauco***, Gisele Bacanelli/ ${ }^{++}$, \\ Maristeli B O liveira/ ${ }^{++}$, Lenita R Santos****
}

\author{
Embrapa Gado de Corte, Rodovia BR 262, km 4, 79002-970 Campo Grande, MS, Brasil *Departamento de Medicina \\ Veterinária, UFRPe, Recife, PE, Brasil **Departamento de Computação e Estatística, UFMS, Campo Grande, MS, Brasil \\ ***Instituto de Biologia Molecular do Paraná, Curitiba, PR, Brasil ****Pós-Graduação em Imunologia, Instituto de Ciências da \\ Saúde, UFBA, Salvador, BA, Brasil
}

Indirect enzyme-linked immunosorbent assays (ELISAs) based on recombinant MSP1 a and MSP2 from a Brazilian isolate of Anaplasma marginale were developed to detect antibodies against this rickettsia in cattle. The high sensitivities (99\% for both tests) and specificities (100\% for both tests) were confirmed with sera from cattle positive or negative for A. marginale antibodies, respectively, by immunofluorescent antibody test. By the analysis of 583 sera from cattle of three regions of the state of Pernambuco, Brazil, the agreement between both tests was high, with a kappa index of 0.89. The similar performances of the ELISAs suggest that both tests can be used in epidemiological surveys for detection of antibodies to A. marginale in cattle.

Key words: Anaplasma marginale - indirect enzyme-linked immunosorbent assays - major surface proteins - Brazil

Anaplasmosis is a tick-borne cattle disease caused by the rickettsia Anaplasma marginale, which is endemic in tropical and subtropical areas of the world. The disease causes considerable economic loss to both dairy and beef industries worldwide (Kocan et al. 2003), and is characterized by fever, anemia, general weakness, pale mucous membranes, weight loss (Ajayi et al. 1978), abortion (Correa et al. 1978), decreased milk production, and mortality during the acute phase of infection (Palmer et al. 1986).

A variety of serological tests, such as indirect fluorescent antibody test (IFAT) (Lohr et al. 1973), complement fixation (Gainer 1961), agglutination test (Welter \& Zuschek 1962), and enzyme-linked immunosorbent assay (ELISA) (Luckins 1977) have been used to detect antibodies to A. marginale. Although sensitivities of these assays were considered acceptable, there is potential for false-positive reactions when crude antigens are used, due to the contamination with erythrocyte components (Barry et al. 1986).

Advances in biochemical, immunologic, and molecular technologies during the last decade have been applied to research of A. marginale (Kocan et al. 2003). As a result of these studies, the major surface proteins (MSPs) with potential for diagnostics were identified (Palmer et al. 1986, Oberle et al. 1988, Visser et al. 1992).

Financial support: Fundect, $\mathrm{CNPq}$

+Corresponding author. E-mail: flabio@cnpgc.embrapa.br

${ }^{++}$Research fellow CNPq

Received 4 May 2005

Accepted 26 August 2005
The objectives of the present study were to develop, evaluate, and compare ELISAs based on recombinant MSP1a and MSP2, two immunodominant membrane proteins of A. marginale.

\section{MATERIALS AND METHODS}

A. marginale isolate - Infected blood was obtained by the inoculation of a splenectomized Nelore calf with a Brazilian isolate of A. marginale (Pernambuco, Zona da Mata). Blood was collected in vacuum tubes with heparin when rickettsemia reached $87 \%$.

$D N A$ purification and $P C R$ - DNA was purified from $350 \mu \mathrm{l}$ of infected blood by Easy DNA kit (Invitrogen, US). Based on the reported mspla and msp2 nucleotide sequences (Genbank accession numbers: AY010247 and AF317726, respectively), primers were designed to amplify a fragment of mspla that encodes the hydrophilic domain of MSP1a, and a fragment of $m s p 2$ that encodes part of the $\mathrm{N}$ terminal region, the hypervariable region and the $\mathrm{C}$ terminal region of MSP2. These primers were msplaF (5' GGGTACGCCACCTATCTCGC $3^{\prime}$ ) and msplaR (5'AACAAGCTGTGTAGTAGTGTCCGAAGG3); msp2F (5' GCAGGCGGCGAGGGTCTATTTTCA 3'), and msp2R (5'AGAATCCCCCTAAGCGTTGCCGAACCTCAA 3'). PCR amplification reaction mixture was prepared in a volume of $50 \mu \mathrm{l}$, containing $10 \mathrm{mM}$ tris- $\mathrm{HCl}(\mathrm{pH} 8.3), 50 \mu \mathrm{M}$ $\mathrm{KCl}, 1.5 \mathrm{mM} \mathrm{MgCl}_{2}, 0.2 \mathrm{mM}$ (each) deoxynucleoside triphosphate, $100 \eta \mathrm{g}$ (each) primer, $100 \eta \mathrm{g}$ of genomic DNA, and 2.5 U of Taq DNA polymerase (Cenbiot, Brazil). Amplification was performed in a PTC-200 thermocycler (MJ Research, US) as follows: $94^{\circ} \mathrm{C}$ for 1 min (denaturation); the next 35 cycles were $94^{\circ} \mathrm{C}$ for $1 \mathrm{~min}$ (denaturation), $61^{\circ} \mathrm{C}$ (mspla) or $60^{\circ} \mathrm{C}$ (msp2) for $1 \mathrm{~min}$ (annealing), and $72^{\circ} \mathrm{C}$ for $1 \mathrm{~min}$ (mspla) or $1.5 \mathrm{~min}$ (msp2) (extension), and the last cycle was $72^{\circ} \mathrm{C}$ for $7 \mathrm{~min}$ (extension). PCR products were 
analyzed by electrophoresis in $1 \%$ agarose gel, stained with ethidium bromide $(0.5 \mu \mathrm{g} / \mathrm{ml})$.

Cloning and expression of mspla and msp2 - PCR amplicons were cloned in plasmid $p \operatorname{TrCHisTOPO}$ (Invitrogen), according to the manufacturer's instructions. The recombinant plasmids were used to transform Escherichia coli TOP10 cells (Invitrogen). Insert orientation was determined by colony PCR, using the vector forward primer Xpress (Invitrogen) and insert reverse primers. The inserts were also sequenced in both directions by the dideoxide method and analyzed in an ABI 3100 automatic sequencer (Applied Byosystems, US). Only sequences with a PHRED index greater than 20 were considered.

Overnight $50 \mathrm{ml}$ cultures of TOP 10 cells carrying the recombinant plasmids ( $p$ TrcHisTOPO-mspla and

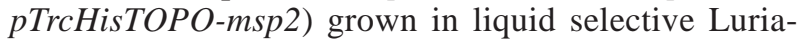
Bertani (LB) medium containing $100 \mu \mathrm{g} / \mathrm{ml}$ of ampicillin (LB-amp) were cultured each one in $450 \mathrm{ml}$ of LB-amp for $1 \mathrm{~h}$ at $37^{\circ} \mathrm{C}$. Isopropyl- $\beta$-D-thiogalactopyranoside (IPTG) was added at a final concentration of $1 \mathrm{mM}$. The cultures were allowed to grow for $6 \mathrm{~h}$. Aliquots of $2 \mathrm{ml}$ were taken before induction with IPTG and then every $2 \mathrm{~h}$. These aliquots were centrifuged at $18,000 \mathrm{x} \mathrm{g}$ and pellets were frozen at $-20^{\circ} \mathrm{C}$. After a 6 -h culture, TOP 10 cells were recovered by centrifugation at $10,000 \mathrm{xg}$ for $10 \mathrm{~min}$. Pellets were suspended in $20 \mathrm{ml}$ of $50 \mathrm{mM}$ phosphate buffer and then frozen in liquid nitrogen. After thawing at $4^{\circ} \mathrm{C}$, suspensions were sonicated (Branson Sonifier 250, US - output 40) 6 times for $20 \mathrm{sec}$ on ice. The production of recombinant proteins was verified by SDS-PAGE, followed by Coomassie blue staining.

Purification of recombinant proteins - Purifications of recombinant MSP1a and MSP2 (rMSP1a and rMSP2) were performed by affinity chromatography, using agarose-nickel resin (ProBond Purification kit, Invitrogen), following the manufacture's instructions. A hybrid protocol, with lysis under denaturing conditions and washes and elution steps under native conditions, was used. $\mathrm{Pu}$ rity was verified by SDS-PAGE, followed by Coomassie blue staining.

Western blot - The antigenicity of rMSP1a and rMSP2 was tested by Western blot with sera of immune cattle from different regions of Brazil (states of Pernambuco, Paraná, and Mato Grosso do Sul). A Western blot with recombinant MSP2 and monoclonal antibody (MoAb) ANAO70A2, specific for this protein (McGuire et al. 1984), was also performed.

ELISAs - Optimal dilutions of rMSP1a and rMSP2, sera and conjugate were determined by testing six sera negative for A. marginale antibodies, from cattle kept in an isolation area of Embrapa Beef Cattle, Campo Grande, MS, Brazil, and six sera positive for A. marginale antibodies, from experimentally-infected cattle.

For determination of the concentrations of rMSP1a and rMSP2, these proteins and known concentrations of human serum albumin were submitted to SDS-PAGE, stained with Coomassie blue, and then analyzed by Alpha-DigiDoc software (Alpha Innotec, US).
For the recombinant ELISAs, 96-well plates (Greiner Bio One, Microlon, Austria, ref. 655001) were adsorbed with $10 \eta \mathrm{g} / \mathrm{well}$ of rMSP1a or $5.7 \eta \mathrm{g} / \mathrm{well}$ of rMSP2, diluted in Dulbelcco's phosphate buffer, $\mathrm{pH}$ 7.2, for $4 \mathrm{~h}$, at $4^{\circ} \mathrm{C}$. Plates were blocked with $5 \% \gamma$-globulin free equine serum diluted in phosphate buffer saline with $0.1 \%$ Tween (PBST), for $60 \mathrm{~min}$, at $37^{\circ} \mathrm{C}$. After three washes with PBST, control and test sera, diluted 1:600 in PBST, were incubated for $60 \mathrm{~min}$ at $37^{\circ} \mathrm{C}$. Plates were then washed five times with PBST, and rabbit anti-bovine IgG horseradish peroxidase conjugate (Sigma, US, ref. A-7414), diluted $1: 10,000$ in PBST, was added to the wells. Plates were incubated for $30 \mathrm{~min}$ at $37^{\circ} \mathrm{C}$ and after five washes with PBST, the chromogen/substrate $o$-phenylene diamine dihydrochloride (OPD; Sigma)/ $\mathrm{H}_{2} \mathrm{O}_{2}$ was added. The reaction was stopped by addition of $\mathrm{H}_{2} \mathrm{SO}_{4}(2.5 \mathrm{~N})$ and results were read on a Bio-Tek EL-800 ELISA reader (US), with a $490 \eta \mathrm{m}$ filter.

Cut-offs were determined for each plate with 12 negative control sera, according to Frey et al. (1998). A 99\% confidence interval was used.

One hundred and seven sera positive for A. marginale antibodies by IFAT, from naturally-infected cattle of the states of Mato Grosso do Sul (nr 25) and Goiás (nr 61), Brazil, and sera from experimentally-infected calves (nr 21), were used for determination of sensitivity. Eighty nine sera negative for A. marginale antibodies by IFAT, from cattle of the state of Rio Grande do Sul (nr 27), Brazil, and from cattle raised in a tick-free isolation area of Embrapa Beef Cattle (nr 62), were used for determination of specificity. Positive and negative predictive values were also determined with these sera.

Five hundred and eighteen sera from dairy cross-bred cattle, from both sexes, and varying ages, from three regions of the state of Pernambuco, Brazil (Recife, Zona da Mata, and Agreste), were analyzed by both ELISAs for analysis of agreement between tests.

In the quantitative evaluation of the agreement between the ELISAs with rMSP1a and rMSP2, the kappa index was calculated (Kramer \& Feinstein 1981). To the samples with disagreements, the Fischer's exact test was applied.

\section{RESULTS}

PCRs for msp 2 and mspla-Amplifications of mspla and $m s p 2$ by PCR resulted in fragments of $626 \mathrm{bp}$ and 1,211 bp, respectively (Fig. 1).

DNA sequencing - The cloned fragments were identified (base-calling) using the program PHRED and the consensus sequence was obtained using the program PHRAP. The resulting sequences showed significant alignments, using the program Blastx ( $n r$ data base), with sequences of MSP2 (accession nr AAL26275, e-value $10^{-178}$ ) and MSP1a (accession nr AAP49429, e-value $5 \times 10^{-78}$ ) of $A$. marginale, available at the Genbank.

Expression of mspla and msp2 - The induction of $m s p l a$ and $m s p 2$ with IPTG resulted in protein bands of approximately $33,0 \mathrm{kDa}$ and $42,2 \mathrm{kDa}$, respectively, which were purified by affinity chromatography with agarose/ nickel. rMSP1a was partially soluble, while rMSP2 was completely insoluble (Figs 2, 3). 


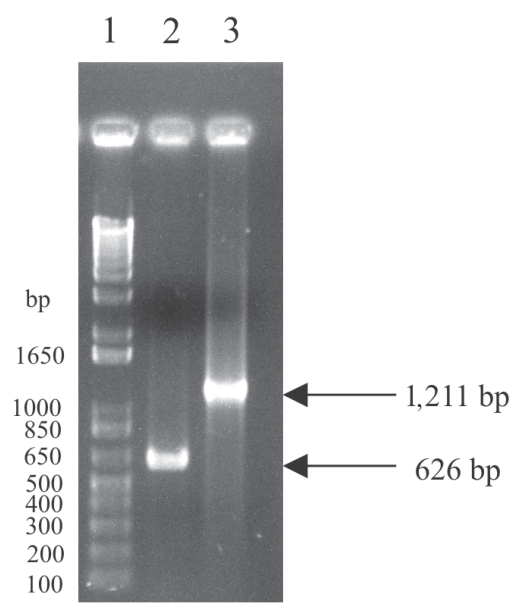

Fig. 1: amplification by PCR of msp1a and $m s p 2$ from a Brazilian isolate (Pernambuco-Zona da Mata) of Anaplasma marginale. Lanes - 1: $1 \mathrm{~kb}$ plus (Invitrogen); 2: mspla fragment; 3: msp2 fragment.

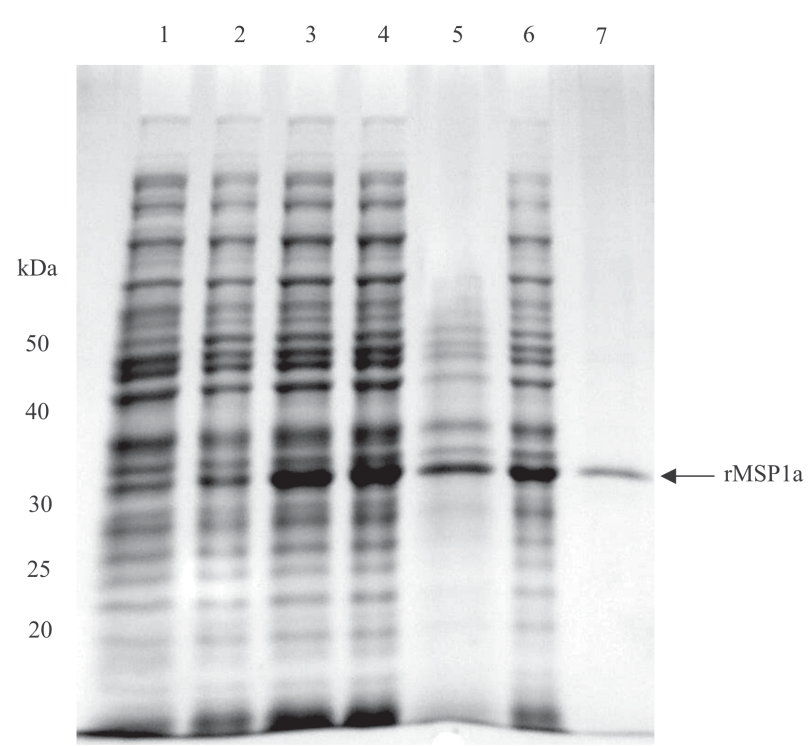

Fig. 2: coomassie blue stained SDS-PAGE profile of Escherichia coli TOP 10 extracts expressing mspla from a Brazilian isolate (Pernambuco-Zona da Mata) of Anaplasma marginale. Lanes - 1: extract of E. coli TOP10 transformed with pTrcHis-TOPO/msp 1a without induction with IPTG; $2: 2 \mathrm{~h}$ induction with IPTG; $3: 4 \mathrm{~h}$ induction with IPTG; $4: 6 \mathrm{~h}$ induction with IPTG; 5: soluble fraction; 6: insoluble fraction; 7: purified recombinant MSP1a.

Antigenic analysis by Western blot - rMSP1a and rMSP2 were blotted onto nitrocellulose membranes after SDS-PAGE and reacted with sera of A. marginale seropositive cattle from different regions of Brazil (Figs 4, 5). Recombinant MSP2 also reacted with monoclonal antibody ANAO70A2 (Fig. 6).

Performances of the ELISAs - Results concerning the sensitivity, specificity, negative, and positive predictive values and precision of the rMSP1a and rMSP2 ELISAs are shown in Table I. The tests showed identical performances.

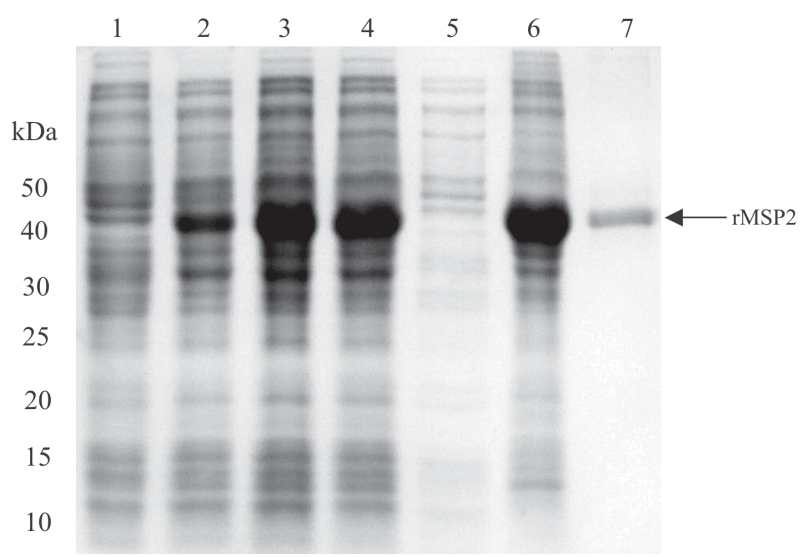

Fig. 3: coomassie blue stained SDS-PAGE profile of Escherichia coli TOP 10 extracts expressing $m s p 2$ from a Brazilian isolate (Pernambuco-Zona da Mata) of Anaplasma marginale. Lanes - 1: extract of E. coli TOP10 transformed with pTrcHis-TOPO/msp2 without induction with IPTG; $2: 2 \mathrm{~h}$ induction with IPTG; $3: 4 \mathrm{~h}$ induction with IPTG; 4: $6 \mathrm{~h}$ induction with IPTG; 5: soluble fraction; 6: insoluble fraction; 7: purified recombinant MSP2.

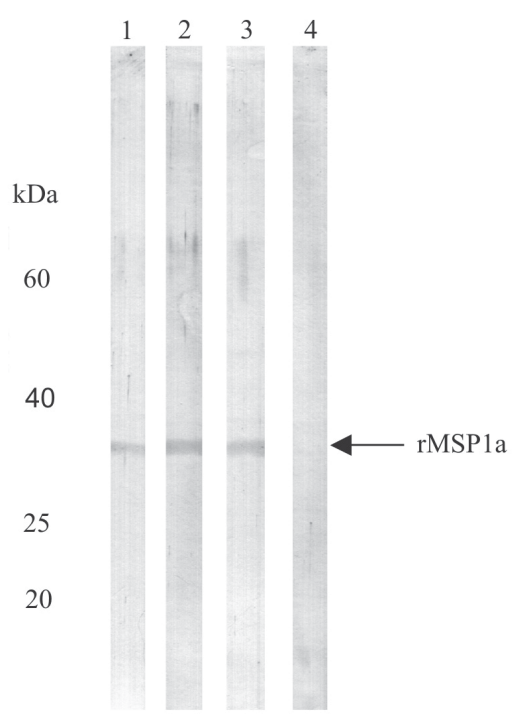

Fig. 4: Western blot with recombinant MSP1a from a Brazilian isolate (Pernambuco-Zona da Mata) of Anaplasma marginale and seropositive cattle sera from different regions of Brazil. Lanes - 1: serum of cattle from state of Pernambuco; 2: serum of cattle from state of Mato Grosso do Sul; 3: serum of cattle from state of Paraná; 4: negative control (serum of cattle from state of Mato Grosso do Sul, negative for A. marginale antibodies by immunofluorescent antibody test).

Agreement between tests - From the 583 sera analyzed, 571 showed identical results in both tests (MSP1a+l MSP2+ or MSP1a-/MSP2-), corresponding to an agreement of $97.9 \%$ (Table II), with a kappa index of 0.89 . With regards to the discrepant results, there was a statistically superior number of MSP1a-/MSP2+ sera than MSP2-/ MSP1a+ sera (P 0.039).

\section{DISCUSSION}

Despite the existence of a central hypervariable region in MSP2, which comprises variable epitopes, including in Brazilian isolates of $A$. marginale (Oliveira et al. 


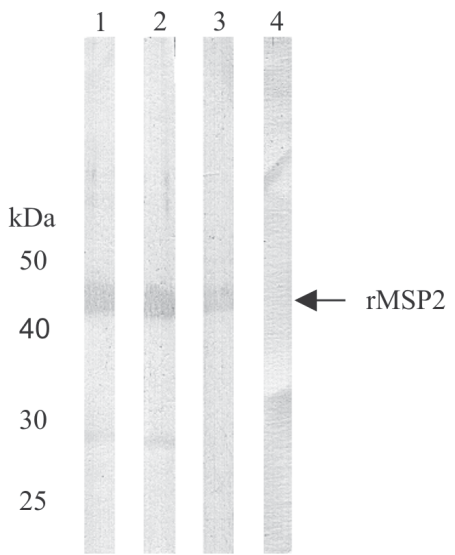

Fig. 5: Western blot with recombinant MSP2 from a Brazilian isolate (Pernambuco-Zona da Mata) of Anaplasma marginale and seropositive cattle sera from different regions of Brazil. Lanes - 1: molecular mass marker (BenchMark, Invitrogen); 2: serum of cattle from state of Paraná; 2: serum of cattle from state of Pernambuco; 3: serum of cattle from state of Mato Grosso do Sul; 4: negative control (serum of cattle from state of Mato Grosso do Sul, negative for A. marginale antibodies by immunofluorescent antibody test).

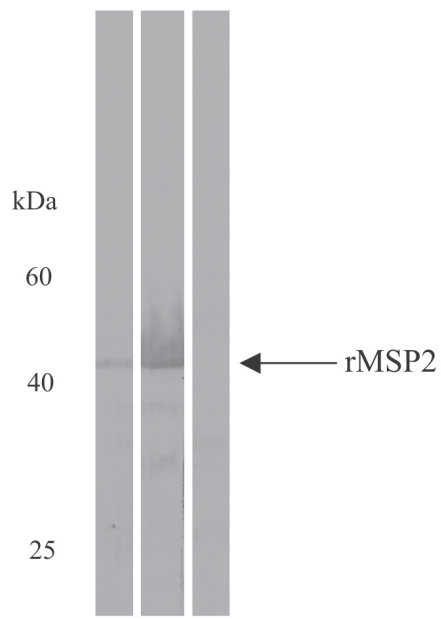

Fig. 6: Western blot with recombinant MSP2 from a Brazilian isolate (Pernambuco-Zona da Mata) of Anaplasma marginale and monoclonal antibody (MoAb) ANAO70A2. Lanes - 1: purified recombinant MSP2; 2: E. coli lysate of a 6 h induction with IPTG; 3: E. coli lysate without induction with IPTG.

2003), this protein exhibits conserved $\mathrm{N}$ and $\mathrm{C}$ termini (French et al. 1999).

MSP1a is composed of an N-terminal region consisting of 28 or 29 amino acid serine-rich repeats that vary in number and sequence among strains and a highly conserved C-terminal region (Allred et al. 1990). Transmembrane protein prediction analysis of MSP1a from the Virginia strain revealed a large hydrophilic domain (HD), extending from amino acids 1 to 366, and a hydrophobic region extending from amino acid 367 to 593 (Brown et al. 2002).

The mspla and $m s p 2$ fragments cloned in this experiment encode for conserved domains, including part of the N-terminal, all the C-terminal regions of MSP2 and the
HD of the C-terminal region of MSP1a. This reflects the recognition of rMSP1a and rMSP2 by sera of cattle from different regions of Brazil in the Western blot and in the ELISAs.

The sensitivities of rMSP1a and rMSP2 ELISAs were high (99\% for both tests), situating between an indirect ELISA with crude antigen (100\%) (Madruga et al. 2000) and a competitive ELISA with recombinant MSP5 and monoclonal antibody (MoAb) ANAF16C1 (96\%) (Torioni de Echaide et al. 1998). The slightly inferior sensitivities of rMSP1a and rMSP2 ELISAs compared to the crude antigen ELISA is probably due to the higher diversity of epitopes in the latter method.

The specificities of rMSP1a and rMSP2 ELISAs (100\% for both tests) were higher than in the indirect ELISA with crude antigen (94\%) (Madruga et al. 2000) and in the competitive ELISA (95\%) (Torioni de Echaide et al. 1998). In the first case, the higher specificity of rMSP1a and rMSP2 ELISAs may be due to the absence of contamination of the antigen with erythrocyte proteins, which are associated with false-positive reactions in the ELISA, due to the reaction of anti-erythrocyte antibodies in the sera (Barry et al. 1986).

TABLE I

Perfomances of recombinant MSP1a and MSP2 ELISAs for Anaplasma marginale antibodies

\begin{tabular}{lccc}
\hline & \multicolumn{3}{c}{ ELISA infection status of the calves ${ }^{a}$} \\
\cline { 2 - 4 } & Positive & Negative & Total \\
\hline rMSP1a & & & \\
Positive & $106(\mathrm{a})$ & $0(\mathrm{~b})$ & $106(\mathrm{a}+\mathrm{b})$ \\
Negative & $1(\mathrm{c})$ & $89(\mathrm{~d})$ & $90(\mathrm{c}+\mathrm{d})$ \\
Total & $107(\mathrm{a}+\mathrm{c})$ & $89(\mathrm{~b}+\mathrm{d})$ & $196(\mathrm{a}+\mathrm{b}+\mathrm{c}+\mathrm{d})$ \\
rMSP2 & $106(\mathrm{a})$ & $0(\mathrm{~b})$ & $106(\mathrm{a}+\mathrm{b})$ \\
Positive & $1(\mathrm{c})$ & $89(\mathrm{~d})$ & $90(\mathrm{c}+\mathrm{d})$ \\
Negative & $107(\mathrm{a}+\mathrm{c})$ & $89(\mathrm{~b}+\mathrm{d})$ & $196(\mathrm{a}+\mathrm{b}+\mathrm{c}+\mathrm{d})$ \\
\hline Total &
\end{tabular}

$a$ : determined by indirect immunofluorescent antibody test (IFAT); according to Coggon et al. (1993):

Sensitivity: a $/(a+c)$ x $100=99 \%$ for both rMSP1a and rMSP2 ELISAs

Specificity: $d /(b+d) \times 100=100 \%$ for both rMSP1a and rMSP2 ELISAs

Positive predictive value: $\mathrm{a} /(\mathrm{a}+\mathrm{b})$ x $100=100 \%$ for both $\mathrm{rMSP} 1 \mathrm{a}$ and rMSP2 ELISAs

Negative predictive value: $\mathrm{d} /(\mathrm{c}+\mathrm{d}) \times 100=98.9 \%$ for both rMSP1a and rMSP2 ELISAs

Precision: $(a+d) /(a+b+c+d) \times 100=99.5 \%$ for both $r M S P 1 a$ and rMSP2 ELISAs

\section{TABLE II}

Agreement between ELISAs with recombinant MSP1a and MSP2 from a Brazilian isolate (Pernambuco-Zona da Mata) of Anaplasma marginale, using sera from three regions of the state of Pernambuco, Brazil

\begin{tabular}{lccc}
\hline ELISA & MSP1a+ & MSP1a & Total \\
\hline MSP2+ & 516 & 10 & 526 \\
MSP2- & 2 & 55 & 57 \\
\hline Total & 518 & 65 & 583 \\
\hline
\end{tabular}


In the second case, the lower specificity of the competitive ELISA compared to rMSP1a and rMSP2 ELISAs may be due to the Maltose Binding Protein (MBP) fused to the MSP5, which could induce false-positive reactions due to the reaction of anti-MBP antibodies in the sera, blocking the reaction of ANAF16C1 MoAb, even after the adsorption step of test sera with MBP (Torioni de Echaide et al. 1998). This protein is absent in rMSP1a and rMSP2 ELISAs, which showed higher sensitivities and specificities. Another advantage of the rMSP1a and rMSP2 ELISAs is that there is no need for monoclonal antibodies nor for adsorption steps of test sera.

The agreement between the two tests was high, defined by a kappa index of 0.89 . The kappa index was used in the present investigation to determine the concordance of the assays with each other and to assess the reliability of the observed agreement, as this test corrects the agreement expected by chance.

With regards to the discrepant results, the statistically superior number of MSP1a-/MSP2+ sera over the MSP2-/MSP1a+ sera may be attributed to a slightly lower sensitivity or a slightly superior specificity of rMSP1a ELISA. However, this is a low magnitude difference, which doesn't represent a clear advantage of an assay over the other, as the agreement between the ELISAs was high.

The high sensitivities and specificities of rMSP1a and rMSP2 ELISAs, associated with the recognition of both antigens by sera from cattle of different regions of Brazil, suggest that these serological tests can be used for epidemiological studies. The similar performances of both tests, with a high agreement in the results, suggest that both tests can be used indistinctly for the detection of $A$. marginale antibodies.

\section{REFERENCES}

Ajayi SA, Wilson AJ, Campbell RS 1978. Experimental bovine anaplasmosis: clinico-pathological and nutritional studies. Res Vet Sci 25: 76-81.

Allred DR, McGuire TC, Palmer GH, Leib SR, Harkins TM, McElwain TF, Barbet AF 1990. Molecular basis for surface antigen size polymorphisms and conservation of a neutralization-sensitive epitope in Anaplasma marginale. Proc Natl Acad Sci USA 87: 3220-3224.

Barry DN, Parker RJ, De Vos AJ, Dunster P, Rodwell BJ 1986. A microplate enzyme-linked immunosorbent assay for measuring antibody to Anaplasma marginale in cattle serum. Aust Vet $J$ 63: 76-79.

Brown WC, Palmer GH, Lewin HA, McGuire TC 2002. CD4 ${ }^{+}$ T lymphocytes from calves immunized with Anaplasma marginale major surface protein 1 (MSP1), a heteromeric complex of MSP1a and MSP1b, preferentially recognize the MSP1a carboxyl terminus that is conserved among strains. Infect Immun 69: 6853-6862.

Coggon T, Rose G, Barker DJ 1993. Measurement, error and bias. In T Coggon, G Rose, DJ Barker (eds), Epidemiology for the Uninitiated, BJM Publishing Group, London, p. 2025.

Correa WM, Correa CN, Gottschalk AF 1978. Bovine abortion associated with Anaplasma marginale. Can J Comp Med 42: 227-228.
French DM, Brown WC, Palmer GH 1999. Emergence of Anaplasma marginale antigenic variants during persistent rickettsemia. Infect Immun 67: 5834-5840.

Frey A, Di Canzio J, Zurakowski D 1998. A statistically defined endpoint titer determination method for immunoassays. J Immunol Meth 221: 35-41.

Gainer JH 1961. Demonstration of Anaplasma marginale with the fluorescent dye, acridine orange; comparisons with the complement-fixation test and Wright's stain. Am J Vet Res 22: $882-886$.

Kocan KM, de la Fuente J, Guglielmone AA, Melendez RD 2003. Antigens and alternatives for control of Anaplasma marginale infection in cattle. Clin Microbiol Rev 16: 698712.

Kramer MS, Feinstein AR 1981. Clinical biostatistics. LIV. The biostatistics of concordance. Clin Pharmacol Ther 29: 111-123.

Lohr KF, Ross JP, Meyer H 1973. Studies on homologous and heterologous antibody responses to infections with Anaplasma marginale and $A$. centrale using the indirect fluorescent antibody and capillary tube agglutination tests. $Z$ Tropenmed Parasitol 24: 86-95.

Luckins AG 1977. Detection of antibodies in trypanosomeinfected cattle by means of a microplate enzyme-linked immunosorbent assay. Trop Anim Health Prod 9: 53-62.

Madruga CR, Marques APC, Leal CRB, Carvalho CME, Araújo FR, Kessler RH 2000. Evaluation of an enzyme-linked immunosorbent assay to detect antibodies against Anaplasma marginale. Pesq Vet Bras 20: 109-112.

McGuire TC, Palmer GH, Goff WL, Johnson MI, Davis WC 1984. Common and isolate-restricted antigens of Anaplasma marginale detected with monoclonal antibodies. Infect Immun 45: 697-700.

Oberle SM, Palmer GH, Barbet AF, McGuire TC 1988. Molecular size variations in an immunoprotective protein complex among isolates of Anaplasma marginale. Infect Immun 56: 1567-1573.

Oliveira JB, Madruga CR, Schenk MA, Kessler RH, Miguita M, Araújo FR 2003. Antigenic characterization of Brazilian isolates of Anaplasma marginale. Mem Inst Oswaldo Cruz. 98: 395-400.

Palmer GH, Barbet AF, Kuttler KL, McGuire TC 1986. Detection of an Anaplasma marginale common surface protein present in all stages of infection. J Clin Microbiol 23: 10781083.

Torioni de Echaide S, Knowles DP, McGuire TC, Palmer GH, Suarez CE, McElwain TF 1998. Detection of cattle naturally infected with Anaplasma marginale in a region of endemicity by nested PCR and a competitive enzyme-linked immunosorbent assay using recombinant major surface protein 5. J Clin Microbiol 36: 777-782.

Visser ES, McGuire TC, Palmer GH, Davis WC, Shkap V, Pipano E, Knowles DP Jr 1992. The Anaplasma marginale msp5 gene encodes a 19-kilodalton protein conserved in all recognized Anaplasma species. Infect Immun 60: 5139-5144.

Welter CJ, Zuschek F 1962. Properties of Anaplasma marginale antigen used in a capillary tube-agglutination test. JAm Vet Med Assoc 141: 595-599. 